Although the process of integrating institutional research into professional practice is still in a formative stage, we have learned some lessons from our experience.

\title{
Lessons Learned: Institutional Research as Support for Academic Improvement
}

\author{
Edward P. St. John
}

As Patton, Morelon, Whitehead, and Hossler showed in Chapter One of this volume, there is, unfortunately, relatively little rigorous research that can inform institutions about best practices in student enrollment and persistence. Although at first this notion may seem counterintuitive, given the substantial volumes of work on educational attainment (Pascarella and Terenzini, 1991, 2005), the void seems traceable to the substantial valuation of traditional persistence models that have not provided a basis for evaluative research, as is evident in reviews of prior research in Chapters One and Three of this volume. Higher education research has been theoretically elegant and statistically sophisticated-providing information on the roles of students' academic and social engagement as intermediate outcomesbut has not adequately responded to the new challenge for public accountability. In particular, there is a need for evaluation of strategies for improvement processes within and across disciplines.

One way of viewing accountability in higher education is to consider accountability schemes that report descriptive statistics on persistence and other outcomes (Zumeta, 2001), but this approach favors institutions that have high persistence rates rather than encouraging and rewarding campuses that attract high-achieving students. Indeed, there is evidence that there are financial advantages for research universities in states with accountability systems (Weerts, 2002). An alternative is to work with common data systems

\section{(3)WILEY}

\section{InterScience ${ }^{\circ}$}


to identify and address challenges facing students and institutions. Evaluative research is needed that examines the impact of academic interventions, controlling for the preparation of students, which means, at a minimum, sound inferential statistical models. The goal of conducting research that can inform practice is not out of reach if we can learn the necessary lessons about standards, theory, and practice-the topics addressed in this volume. As a conclusion, I summarize lessons learned from these chapters, supplemented by other recent literature.

\section{Standards for Research}

With the growing emphasis on government accountability in education, it is important to consider the standards used for research on access, persistence, and other outcomes related to student success and educational attainment. Most of the education research used to build rationales for the education standards movement has focused on correlations between high school courses and subsequent outcomes (Becker, 2004; Heller, 2004) but has failed to consider the direct effects of education policies rationalized on this research. School reforms, accountability standards, and new graduation requirements have been rationalized on such research, but the limited research on the effects of such policies does not support claims about the efficacy of these policies. Rather, most of the K-12 reforms are positively associated with improvement in test scores (Hanushek and Raymond, 2004) but are negatively associated with high school graduation rates (St. John, Musoba, and Chung, 2004).

One possible way to avoid this accountability trap in higher education involves using research to inform improvement efforts within colleges and universities as a means of building cooperation with state agencies. In this approach, it is crucial that administrators and faculty members in the practitioner community, in collaboration with institutional researchers, engage in a serious and dedicated process of research-informed reform. The time commitments required to use this approach may make it difficult to use research-informed change as a universal accountability method. Nonetheless, such an approach merits exploration and further testing.

Even if politics does prevail and new accountability schemes are implemented, it will be important to break down barriers to educational opportunity and to experiment with new approaches to improving outcomes. Thus, whatever position one takes on the future of government accountability schemes in higher education, there is reason to reconsider the role of research. Research-informed improvement efforts may be workable within state systems that have accountability schemes linked to public funding, just as they may provide means of fending off top-down accountability. As difficult as research-informed change has proven to be, it may have merit in states that collect student-record data, regardless of the status of accountability. 
But what standards should education and policy research meet before it can and should be used as a basis for government and institutional decisions about education improvement and finance? The chapters in this volume move a considerable distance toward answering this question. Three lessons emerge as paramount.

Lesson 1: Setting a Minimum Standard for Inferential Research. The minimum standard for inferential research on access and persistence requires sound theoretical foundations and the use of multivariate statistical models that control for the primary independent variables necessary to assess the effects of interventions (in other words, public finance policies or institutional interventions) on attainment outcomes.

The national and state reviews of prior evaluation research revealed that most research does not meet a generally accepted standard for inferential research. In Chapter One of this volume, Patton and colleagues revealed that, while there is extensive persistence research, there have been few studies that actually evaluate interventions based on theory-driven research. In Chapter Two, Braxton, McKinney, and Reynolds took a more in-depth look at evaluation studies that had been conducted previously in Indiana. They found that most studies were descriptive and that few had met a generally accepted standard for inferential research.

Descriptive information about differences in rates does not meet a minimum threshold for evaluation for two reasons: it does not control for other variables that influence the intended outcomes, and it does not control for selection (institutional or self-selection) in the analysis of effects. This standard meets one aspect of the goal: controlling the influence of other variables. The fact that so much of the evaluation research in higher education fails to meet even a minimum standard for inferential research reveals that institutions do not have adequate evaluative information for institutional decisions about educational improvement.

Lesson 2: The Need for Solid Design. To make causal inferences about interventions (public finance policies or institutional interventions) it is necessary to use experimental designs with random assignment or to test and control for selection effects.

Research that meets the inferential standard has generally been considered acceptable for higher education research and provides a reasonable basis for institutional decisions. However, most research on the effects of programs on students in higher education fails to control for selection-institutional decisions about eligibility and student self-selection decisions—so they stop short of providing causal information about interventions even when they examine direct and indirect effects. This newer standard for determining causal effects of intervention is now a federal requirement in education research (No Child Left Behind Act, 2001) and is crucial for research on educational attainment (Becker, 2004).

The random assignment of students and faculty into treatment and control groups may be desirable from an empirical vantage point, but 
frequently it is not possible in higher education, given the preference for student freedom to choose and faculty freedom to teach. Nevertheless, this higher standard poses a challenge for researchers in higher education as to how to address methodological issues related to selection. When an inferential standard is met and a variable for an intervention is significant in a logically sound model, we can be confident that involvement in the intervention made a difference, but we do not know if the difference was caused by selection (for example, students choosing to participate) or by the intervention itself. Higher education researchers such as DesJardins (2005) are engaged in testing the use of instrument variables to control for selection (by institutions or as self-selection by students), regression discontinuity analysis, and other methods for untangling questions related to selection.

Given the state of knowledge, it is important to check whether or not involvement in interventions is random if inferential models are used. In Chapter Six of this volume, Musoba recognized this limitation. The state of the art in attainment research is in transition due to higher expectations of educational research and the use of statistical methods in sociology and education, and it will be necessary to make adjustments in evaluation research as well.

Lesson 3: The Benefits of Qualitative Research. Qualitative research on enrollment, persistence, and other attainment outcomes can enrich and illuminate understanding of linkages hypothesized by theoretical models, reveal critical challenges overlooked by theory, and provide explanations for the effects of public policies and institutional interventions.

In higher education, researchers cannot rely exclusively on empirical research methods. Given the array of accepted ways of knowing in academe, even the best quantitative research will be overlooked by many in academe. Ideally, both quantitative and qualitative methods should be used in research on educational outcomes. In this volume, Hansen and Borden (Chapter Four) and St. John, McKinney, and Tuttle (Chapter Five) describe how qualitative methods can be integrated into institutional research and used to inform change processes.

Institutional research as a field-like policy studies-must meet generally accepted empirical standards, given the nature of decision-making processes. However, qualitative studies are also needed to build understanding of challenges and effects of interventions. In fact, while empirical studies are needed to provide proof of effects, qualitative studies are often necessary to build an understanding of the reasons that interventions worked or failed as well as to reveal ways that practices might be altered to improve outcomes.

\section{The Theory Problem Reconsidered}

Theory plays a crucial role in research on educational attainment because it guides the selection of variables for statistical models, the assignment of indi- 
viduals to treatment groups in random experiments (characteristics for selection), and the interpretation of results in both quantitative and qualitative research. Therefore, it is important that institutional researchers reconsider the role of theory, rather than select one theory because of its dominance in the literature over others. Three lessons emerge from this consideration.

Lesson 4: Theories of Persistence. While a substantial amount of persistence research uses generally accepted theory, there has been relatively little prior evaluation research on persistence interventions that meets a minimum standard for inferential research.

Theories of involvement and engagement dominate research on student persistence (Braxton, 2000; Hossler, Bean, and Associates, 1990; Pascarella and Terenzini, 2005). There are three major problems with using this theory as the primary basis for research that evaluates the effects of interventions and public policy on educational attainment.

First, as described in Chapters One and Two of this volume, this area of research has been used to rationalize interventions but has not been used to evaluate the effects of interventions rationalized on the basis of the theory. Since the theory focuses largely on involvement and engagement as measures of integration, it provides a basis for recommending involvement strategies, as discussed in Chapters One and Three of this volume, but does not provide a rationale for evaluating other types of interventions. For this task we need a better theory base for examining outcomes related to attainment.

Second, recent studies document that student engagement is influenced by family income and student aid (Hurtado, Nelson-Laird, and Perorarzio, 2004; Sedlacek and Sheu, 2004). The current work-loan burden after needbased grant aid is substantial—about $\$ 8,000$ per year on average for student families earning less than $\$ 25,000$ (Advisory Committee, 2002). It requires many hours of work to pay this annual bill, which reduces time for student involvement. Therefore, engagement theories require reformulation based on recent research on the role of finances. There may be a need to reconceptualize engagement theories of persistence to integrate an understanding of the role of family income and student aid in enabling student involvement. It is important to build on understandings from social and economic research rather than pursue a separate line of inquiry with limited relevance to policy or evaluation.

In spite of these limitations, our theories of persistence have provided a substantial contribution to the field of higher education. In particular, theory and research on student integration provide a lens through which to view student involvement in academic process, including interaction with faculty. For example, this body of work has influenced the emergence of learning communities. However, the task remains to evaluate these new models using balanced models that consider the roles and influence of social and economic background on student involvement. In addition, this area of theory could inform a new generation of work that examines problems specific to different academic fields, a crucial issue in the period ahead. 
Lesson 5: Using a Sound Base of Social and Economic Theory. Research on the effects of interventions (public finance policies or institutional interventions) should consider social theory and research on attainment as well as economic theory and research in the design of models for examining enrollment, persistence, and other attainment-related outcomes.

To meet the standards for inferential or causal research on the impact of institutional interventions and public policies, it is necessary to use a sound theory base. The theories of fit integration and engagement widely used in higher education research are not adequate to this task when used as the primary theory base because they overlook the substantial role of inequalities in preparation for and involvement during college resulting from income inequalities. It is crucial to step back and consider social and economic theories when considering the roles of involvement or engagement, interventions, and financial aid.

Social theory has long focused on the role of family backgroundincluding parents' income-in the attainment process (Alexander and Eckland, 1978; Blau and Duncan, 1967). More recently, the concepts of social capital and cultural capital have been used as explanations for the role of social force. The cultural capital argument views the link between family culture and education attainment as central (Bourdieu, 1980), while social capital focuses on the role of networks and other mechanisms that are linked to opportunity (Coleman, 1988). Both theories have been widely used in higher education research on attainment processes. Regardless of the specific explanation used to interpret the role of social forces, it is important to consider these variables as foundational.

Economic theory, too, has been central to research on attainment process for decades, especially in research on college students. Human capital theory (Becker, 1964)—especially the argument that individuals and government consider the costs and benefits of investment in educationhas been used in research on college students (see, for example, Jackson, 1978; Manski and Wise, 1983) and has been a major argument. More recent studies that establish linkages between finances (income and financial aid) and both preparation (St. John and others, 2004) and integration during college (Hurtado, Nelson-Laird, and Perorarzio, 2004; Sedlacek and Sheu, 2004) provide even more compelling evidence that the role of finances is integral to attainment.

Lesson 6: Using Existing Data. Institutional records on high school preparation, student aid, admissions, and student enrollment (that is, workable models) provide a basis for models that evaluate the effects of interventions on attainment outcomes, provided that information of involvement in interventions is also available.

Institutional record systems developed from data normally collected from schools, colleges, and other agencies provide an appropriate database for research on educational attainment. In the study summarized in Chapter Six of this volume, Musoba demonstrates that this approach can also be extended 
to the analysis of the effect of intervention programs. Although empirical studies are crucial for evaluation purposes, qualitative studies may be even more important as means of building understandings among practitioners, as discussed by Hansen and Borden in Chapter Four of this volume and by St. John, McKinney, and Tuttle in Chapter Five. Institutional researchers should use both methods in studies aimed at informing institutional change processes, as argued by Hansen and Borden and illustrated by other chapters in this volume.

\section{Collaborations Between Researchers and Practitioners}

In Chapter Four of this volume, Hansen and Borden challenge all of us to think about strategies for building collaboration between institutional researchers and practitioners in higher education (such as administrators and faculty) to address critical challenges. The Indiana Project for Academic Success (IPAS) used an action inquiry approach for both through assessment to identify critical challenges and through action inquiry to find new solutions for them. While IPAS is a work in progress, it is possible to learn from the experience to date.

Lesson 7: Academic Challenges Remain. Although substantial gains are apparently being made in retention during the first two years of college, there are also critical challenges related to persistence to degree completion. It is especially important to focus on building an understanding of academic success within and across academic fields, particularly for studies that consider how major choices-and even how performance in tough courses in those majors-influence persistence.

The academic disciplines are at the core of academic communities and form the basis for the academic programs in most institutions of higher education. Higher education research on college students has informed innovations in course delivery for first-year students, a type of intervention that is now being evaluated (as Musoba describes in Chapter Six of this volume), but that has stopped short of providing a basis for designing interventions within academic fields.

There are numerous academic challenges that merit attention. For example, the humanities disciplines have lost students in recent decades due in part to the low earnings of graduates in these fields (Bradburn and others, 2003). Historically, the humanities and liberal arts were thought to be preparation for professional employment. In this new context, perhaps these fields are preparation for graduate professional programs, an issue that merits consideration. Not only is there a need for innovations that link the humanities with the professions as part of undergraduate programs, but such interventions should probably be pilot tested and evaluated.

One major challenge is for institutional researchers and interested faculty to work together on addressing learning issues within their academic fields. This involves not only building pedagogical content knowledge within fields but also finding better ways to integrate information on student 
involvement in academic innovations with balanced models that control for student background. A new generation of innovation and research is needed to explore the academic pathways students travel to academic success.

Lesson 8: Using Workable Models. Workable models for enrollment, major choice, and persistence can be used to identify critical challenges as part of a systematic assessment process, including analyses within and across academic fields.

As described elsewhere in this volume, the assessment process used in IPAS involved examining extant databases to identify critical challenges. Analyses were conducted at the state level and for participating campuses. Statewide, it was evident that there were challenges for African American students with respect to academic integration, as measured by persistence in academic fields. In Chapter Three of this volume, Carter reviews the literature on persistence by African Americans and finds research on social integration and financial aid, but relatively little information on academic integration within major fields. Thus, a near void in the literature, echoing findings from the national review described in Chapter One, represents the challenge uncovered in the statewide assessment. Using extant data and sound theoretical models (in other words, workable models) can lead to the identification of challenges that face practitioners. However, the literature on best practices did not align well with many of the challenges facing campuses in Indiana.

This method can be adapted by college campuses, and institutional researchers can work directly with strategic planning groups to use institutional data to identify the critical challenges facing their campuses. At the very least, the workable models approach can supplement the assessment methods more common in higher education (see, for example, Banta and others, 2002). Literature reviews provide a further source of information about best practices, although the reviews presented in Chapters One, Two, and Three of this volume suggest a misalignment between challenges and these practices.

Lesson 9: Action Inquiry and Institutional Context. Using action inquiry can overcome the problem of solutions seeking problems (and the paradox in the notion of best practices) in efforts to address critical challenges.

Whether or not there is a sound literature on best practices as they relate to challenges revealed through research, it is important that decisions about strategies to be implemented be informed by an understanding of the institutional context. As discussed in Chapters Four and Five of this volume, action inquiry can be used toward this end.

The paradox in the notion of best practices is the implication that there is a set of practices or processes that should be universally used to improve outcomes, whereas matching interventions with contexts and evolving interventions within their contexts are essential to best practice. Scanning the literature to find practices that have worked in other contexts is only a starting point for action inquiry. For example, when features of the nowpopular concept of linking a set of courses for a group of students in learn- 
ing communities are adapted in commuter campuses, it is necessary to address differences in learning and living environments for both students and faculty. Using an inquiry-based approach can help a faculty working group decide whether and how to adapt this type of strategy.

The case examples in Chapter Five illustrate the inquiry process, which starts with building an understanding of why a problem exists in the first place. If a commuter campus has a persistence problem with first-year students, the campus may decide to try out the learning communities approach. However, if its students are mostly part time and are at greatest risk of not returning for their second fall term, then the campus might want to test the idea of using a set of connected courses that span three or more terms, rather than a one- or two-term approach. Understanding the problem-considering whether first- to second-term persistence or continuous enrollment is the problem during the first two or three years-is important to consider before identifying and selecting possible practices.

Lesson 10: Collaborations. Collaborations between researchers and practitioners can be used to inform the organizational change process.

Several of the chapters in this volume illustrate the importance of collaboration between researchers and practitioners. Hansen and Borden (Chapter Four) make a strong argument for such collaboration, a position that influenced the design of IPAS. The IPAS project experience further reflects the importance of collaboration, as a couple of examples illustrate.

Focus groups conducted by IPAS consultants have been an important part of the early inquiry process, providing a means of bringing students' voices into the process (see Chapter Five). In fact, we have found the focus groups generally seem more open when they are run by an independent researcher. When practitioners-faculty members or student affairs administrators-run focus groups in their own programs, discussions tend to be less frank and open, and positive comments are emphasized. If the role of the early stages of the inquiry process is to uncover the reasons that a challenge exists, then openness is crucial. Independent campus researchers may be able to provide this type of support for practitioners engaged in inquiry aimed at building an understanding of the challenges they face. Such a service can be provided by institutional research offices or by graduate students in higher education programs.

In addition, researchers should be involved in the design of interventions if the aim is to learn from them as pilot tests. In Chapter Six of this volume, Musoba describes the reasons for these linkages and gives an illustrative example from an evaluation. Involving researchers in the design of the interventions can make it easier to collect evaluative information during the intervention. Such a collaborative approach distinguishes pilot tests of the type proposed in Chapter Five from other innovations in practice. The limitation of innovation without a research component is that new understanding might not be shared beyond a very limited community of practice. Yet the problem with treating interventions as pilot tests is that it is a more labor-intensive process requiring the support of researchers. 
Given the labor-intensive nature of the action inquiry process, it seems important to focus the process on the issues that are most crucial to improving student success. Not all adaptations to practice merit the time investment of extensive inquiry; in fact most do not. Therefore, it is crucial to select challenges as outcomes of the assessment process carefully, choosing topics that merit time and have a group of interested practitioners.

Lesson 11: Funding. Integrating evaluative research into strategic planning and budgeting processes within institutions continues to be a challenge.

In theory, planning and budgeting processes should be designed to use evaluative information in deliberations about policy decisions. In the IPAS project there have been a few early examples of campuses securing funding for the action inquiry process. For example, three of the campuses in the northwest corner of the state received funds to conduct surveys of working students, a collaboratively defined challenge area. Other campuses have provided release time for faculty who are engaged in the IPAS process. The IPAS project could not provide minigrants to participating campuses, so practitioner involvement was voluntary. Variability in involvement resulted, it seemed, from the local enthusiasm of practitioners and both the extent and quality of assistance provided (hypotheses that will be tested in a subsequent formative evaluation). However, one of the project aims is to inform institutional budgetary decisions. Involved practitioners often hoped to get funding for projects that proved successful. From a project-management perspective, there is still a question, too, whether campuses will invest in areas that could have promising results.

These questions are important from the perspective of funding agencies as well. Very often, funding is given for projects based on a hope that they will be sustained by the campuses after the project ends. In this case, the aim is to provide professional development and to test the notion of integrating research and practice in action inquiry to address critical challenges. It remains to be seen if this project will create a residual of learning and of using research-based inquiry to make institutional investment decisions. In other words, the IPAS project is an experiment with a new form of practice, and events will determine what can be learned.

Lesson 12: Using State Data Systems. State data systems can be used to inform improvement processes in higher education when the barriers to collaboration are removed.

The IPAS project has demonstrated that state databases can be used in systematic ways to promote improvement. The same process is possible within institutional systems, given that state data are collected from institutions in the first place. Colleges and universities can follow a similar process using institutional data but may lack some information on high school courses and transfer within the state system. The additional data from the state on high school courses, financial aid applications, and transfer made the use of state data more appealing in this case. Several states now have statewide databases that combine information on high school students, college students, and employment. Linking these databases to track students 
over time is important because it can help us to build an understanding of preparation, enrollment, choice of major, and employment outcomes. It may be desirable for other institutions and state agencies to collaborate on the use of data to inform innovations, using methods similar to those tested in Indiana.

There are many other potential uses of state databases to encourage academic reform. Most require the process of carefully linking data to track student progress over time. In states with large-scale data systems, it makes good sense to put them to use in support of institutional improvement. Our experience with the use of state data systems may encourage others to try out a similar process.

\section{Conclusions}

The early twenty-first century has been a period of rising public expectations for high school preparation and college attainment. Many states have taken steps toward increasing high school graduation requirements, and a few have put need-based grant programs in place to ensure opportunity for students who prepare. There are many remaining questions about whether these new policies will have their intended effects. However, colleges and universities are facing the challenge of how best to respond to the new mandate for expansion. Rather than wait and see how the new policies turn out, it is important that institutions of higher education position themselves to respond to the new challenges of expanding opportunity for a new generation of first-time students. This volume has taken a step forward in the debate about expanding opportunity by addressing three interrelated issues related to research on persistence and other attainment outcomes.

First, there are methodological issues facing institutional researchers and practitioners in higher education who are interested in creating more and better pathways to educational success. Many eloquent studies of persistence have been conducted, but there has been relatively little evaluative research on the interventions rationalized based on this research. Most of the research on best practices has not met a generally acceptable inferential statistical research standard-a standard that should be met to confirm that new practices have their intended effect. In addition, a higher research standard should be considered, one that involves testing for the effects of self-selection and official selection processes. In addition to meeting reasonable standards for statistical research, it is important to consider the role of qualitative inquiries in building an understanding of the challenges facing college faculty and student affairs practitioners who are on the front line in the efforts to respond to new educational challenges in higher education. Not only do qualitative studies bring students' voices into the change process, but they also help illuminate the problems in ways that make those problems more understandable for most practitioners, building a better base for collaboration. 
Second, the goal of expanding college opportunities in the United States requires a rethinking of the theories used in research on student persistence. Most persistence theory is relatively silent about the role of financial inequalities, yet the most serious problem with research on student engagement and involvement may be that it largely overlooks the influence (that is, the workloan burden after grants) of scarce family resources on hours worked, time for courses and faculty interaction, and opportunities for social engagement. However, even the use of cultural and social capital theories-concepts that illuminate the role of families-can overlook the role of finances unless studies are carefully crafted. Creating educational programs that meet the educational needs of working students represents an especially critical challenge in higher education, given the problems with financial access.

Third, the process of addressing basic challenges related to expanding and improving educational opportunity necessarily requires collaboration between researchers and practitioners. To address these new challenges will require more than applying known practices thought to be "the best" because they are aligned with theory or because they have worked with traditional college students. Rather, responding to the learning needs of new first-generation students will mean pioneering new educational pathways. In this volume, we present some preliminary evidence related to the use of action inquiry to address critical challenges. This approach holds some promise, but there is a great deal more to be learned.

\section{References}

Advisory Committee on Student Financial Assistance. Empty Promises: The Myth of College Access in America. Washington, D.C.: Advisory Committee on Student Financial Assistance, 2002.

Alexander, K. L., and Eckland, B. K. "Basic Attainment Processes: A Replication and Extension, 1999." Sociology of Education, 1978, 48(4), 457-495.

Banta, T. W., and Associates. Building a Scholarship of Assessment. San Francisco: JosseyBass, 2002.

Becker, G. S. Human Capital: A Theoretical and Empirical Analysis with Special Reference to Education. New York: Columbia University Press, 1964.

Becker, W. E. "Omitted Variables and Sample Selection in Studies of College-Going Decisions." In E. P. St. John (ed.), Readings on Equal Education. Vol. 19: Public Policy and College Access: Investigating the Federal and State Roles in Equalizing Postsecondary Opportunity. New York: AMS Press, 2004.

Blau, P. M., and Duncan, O. D. The American Occupational Structure. New York: Wiley, 1967.

Bourdieu, P. The Logic of Practice (R. Nice, trans.). Stanford, Calif.: Stanford University Press, 1980.

Bradburn, E. M., and others. Baccalaureate and Beyond: A Descriptive Summary of 1999-2000 Bachelor's Degree Recipients, One Year Later-with an Analysis of Time to Degree. NCES no. 2003-165. Washington, D.C.: National Center for Education Statistics, 2003.

Braxton, J. M. "Reinvigorating Theory and Research on the Departure Puzzle." In J. M. Braxton (ed.), Reworking the Student Departure Puzzle. Nashville, Tenn.: Vanderbilt University Press, 2000. 
Coleman, J. C. "Social Capital in the Creation of Human Capital." American Journal of Sociology, 1988, 94, S95-S120.

DesJardins, S. L. Investigating the Efficacy of Using Selection Modeling in Research of the Gates Millennium Scholars Program. Presented to the Gates Millennium Scholars Research Advisory Council, 2005.

Hanushek, E. A., and Raymond, M. E. "Does School Accountability Lead to Improved Student Performance?" Working Paper 10591. Cambridge, Mass.: National Bureau of Economic Research, 2004.

Heller, D. E. "NCES Research on College Participation: A Critical Analysis." In E. P. St. John (ed.), Readings on Equal Education. Vol. 19: Public Policy and College Access: Investigating the Federal and State Roles in Equalizing Postsecondary Opportunity. New York: AMS Press, 2004.

Hossler, D., Bean, J. P., and Associates. The Strategic Management of College Enrollment. San Francisco: Jossey-Bass, 1990.

Hurtado, S., Nelson-Laird, T. F., and Perorarzio, T. E. "The Transition to College for Low-Income Students: The Impact of the GMS Program.” In E. P. St. John (ed.), Readings on Equal Education. Vol. 20: Improving Access and College Success for Diverse Students: Studies of the Gates Millennium Scholars Program. New York: AMS Press, 2004.

Jackson, G. A. "Financial Aid and Student Enrollment." The Journal of Higher Education, 1978, 49, 548-574.

Manski, C. F., and Wise, D. A. College Choice in America. Cambridge, Mass.: Harvard University Press, 1983.

No Child Left Behind Act of 2001, Public Law 107-110.

Pascarella, E. T., and Terenzini, P. T. How College Affects Students: Findings and Insights from Twenty Years of Research. San Francisco: Jossey-Bass, 1991.

Pascarella, E. T., and Terenzini, P. T. How College Affects Students: Vol. 2. A Third Decade of Research. San Francisco: Jossey-Bass, 2005.

St. John, E. P., Musoba, G. D., and Chung, C. G. "Academic Access: The Impact of State Education Policies." In E. P. St. John (ed.), Readings on Equal Education. Vol. 19: Public Policy and College Access: Investigating the Federal and State Roles in Equalizing Postsecondary Opportunity. New York: AMS Press, 2004.

St. John, E. P., and others. "Meeting the Access Challenge: An Examination of Indiana's Twenty-First Century Scholars Program." Research in Higher Education, 2004, 45(8), 829-873.

Sedlacek, W. E., and Sheu, H. B. "Correlates of Leadership Activities of Gates Millennium Scholars." In E. P. St. John (ed.), Readings on Equal Education. Vol. 20: Improving Access and College Success for Diverse Students: Studies of the Gates Millennium Scholars Program. New York: AMS Press, 2004.

Weerts, D. J. State Governments and Research Universities: A Framework for a Renewal Partnership. New York: Routledge, 2002.

Zumeta, W. "Public Policy and Accountability in Higher Education: Lessons from the Past and Present for the New Millennium." In D. E. Heller (ed.), The States and Public Higher Education Policy: Affordability, Access and Accountability. Baltimore: Johns Hopkins University Press, 2001.

EDWARD P. ST. JOHN is Algo D. Henderson Collegiate Professor of Education at the Center for the Study of Higher and Postsecondary Education at the University of Michigan. His research focuses on educational policy and public finance in both K-12 and higher education. 